International Journal of Engineering \& Technology, $7(3.18)(2018) 79-82$
International Journal of Engineering \& Technology
WPC
Website www.sciencepubco.com/index.php/IJET
Technical paper

\title{
Assessment of Cutting Profile of AISI 1095 by Using Infrared Radiation Approach
}

\author{
Mohammad Ashaari Kiprawi ${ }^{1}$, Abdullah Yassin ${ }^{1}{ }^{*}$, Syed Tarmizi Syed Shazali ${ }^{1}$, M. Shahidul Islam ${ }^{1}$, Mohd Azrin \\ Mohd Said ${ }^{1}$
}

${ }^{I}$ Department of Mechanical Engineering and Manufacturing, Faculty of Engineering, Universiti Malaysia Sarawak

*Corresponding author E-mail: yabdulla@unimas.my

\begin{abstract}
This research paper determines the relationship between cutting edge temperature, depth of cut, cutting speed, cutting forces and flank wear. The cutting edge temperature is determined by using a pyrometer consists of Indium Arsenide (InAs) and Indium Antimonide $(\mathrm{InSb})$ photocells to detect infrared radiation that are released from cutting tool's edge and cutting forces is measured by using a dynamometer. The machining process experiment is done by end milling the outer surface of AISI 1095 carbon steel. The output signal from the photocell and dynamometer is processed and recorded in the digital oscilloscope. Based on the results, the cutting edge temperature and cutting force increases as the depth of cut increases. Meanwhile, increasing cutting speed resulting in cutting edge temperature increases but decreasing in cutting force due to thermal deformation. Also, existence of progressive flank wear at cutting tool causes an increment in cutting edge temperature and cutting force proportionally.
\end{abstract}

Keywords: Cutting edge temperature; Cutting force; Flank wear; Milling; Thermal deformation.

\section{Introduction}

Material removal operation is important in the machining industry. It can give desired shape to the product based on the user's needs. Temperature measurement of cutting tool during machining process is an important approach to assess the tool wear, cutting performances, cutting operation, and surface integrity of a final product. Currently, most industries and researcher used thermocouple technique and thermographic technique in milling, turning, drilling and grinding to assess the cutting temperature in the machining operation [1].

It is important to identify the cutting temperature of cutting tool. Cutting temperature of Inconel 718, TI6-4 and carbon epoxy fibre composites are studied by [2]. They found that machinability of these materials is closely related to cutting temperature. Cutting temperature variations between up milling and down milling were also investigated by [3]. They found that the temperature for up cutting is increasing gradually during cutting period and stagnant at peak value just after cutting followed by decreases steadily during noncutting period. A different trend is observed in down milling where the cutting temperature reaches maximum temperature instantly after cutting starts then decreases over sequence period. They postulated that the rate of temperature increase in down milling is higher than up milling.

Several researchers have done a study on a rare workpiece such as carbon fibre-reinforced plastics (CFRP) with a cemented carbide end mill tool instead of abrasive water jet (AWJ) as cutting tool. [4] relates transitions of cutting temperature with the surface integrity of machined CFRP and thermal electromotive force at a cutting speed range of $25 \mathrm{~m} / \mathrm{min}$ to $300 \mathrm{~m} / \mathrm{min}$. They observed that the matrix of machined CFRP's surface is not affected even if the cutting speed is as high as $300 \mathrm{~m} / \mathrm{min}$ and therefore it is suitable to use cemented carbide end mill tool to machine CFRP.

Another study on end milling using carbide tool with a difficultto-machine material, TiAl6V4 is performed by [5]. They compare between mathematical models and thermocouple technique at low cutting speed. The output of their research is increasing cutting speed and feed per tooth will increase temperatures at tool-chip interface.

Experimental study of laser-sintered material's machinability by ball end milling is carried out by [6]. Ball end milling tends to have a major fracture when cutting a laser-sintered material. They studied on the effects of machining a laser-sintered material when surrounded by unsintered powder and the condition of cutting tool. The outcomes of their research is life of cutting tool when cutting a molten sintered powder's workpiece is better than a laser-sintered material surrounded by unsintered powder. They found that cutting temperature of cutting molten sintered powder's workpiece is much lower than the latter.

Recently, an experiment to investigate relations between tool wear of TiCN (Titanium Carbo-Nitride) coated cemented carbide with inclination angle of milling process, oblique angle of cutting edge, cutting force, surface roughness and cutting temperature was carried out by [7]. A workpiece is made of $13 \mathrm{Cr}$ Steel and the cutting temperature is measured using thermocouple method. The result of their investigation shows minimum wear of TiCN coated cemented carbide takes place at cutting velocity of $400 \mathrm{~m} / \mathrm{min}$ when cutting speed is changed from $100 \mathrm{~m} / \mathrm{min}$ to $800 \mathrm{~m} / \mathrm{min}$. They

conclude that the optimal cutting speed exists between low wear mechanism of tool and at high velocity conditions.

Based on these literature reviews, an optimum cutting conditions are possible to be found if tool wear, cutting edge temperature, 
and cutting force are known. The findings of the research are useful for the manufacturing industries to enable optimum manufacturing cost for machining process.

\section{Material and Methods}

A vertical machining center is used as a milling machine for the experiment. The workpiece is made of carbon steel AISI 1095. A $20 \mathrm{~mm}$ tool holder with insert carbide is used as a cutting tool. The cutting edge temperature of the cutting tool is measured using a developed pyrometer with an optical fibre. The cutting force is measured using a dynamometer. The experiments are divided into:

i. influences of axial, $A_{d}$ and radial, $R_{d}$ depth of cut on cutting edge temperature and cutting force

ii. influences of cutting speed on cutting edge temperature

iii. influences of extensive cutting length on cutting edge temperature, wear and cutting force

Cutting conditions for each experiment are listed as shown in Table 1 .

Table 1: Cutting parameters for cutting edge temperature experiment

\begin{tabular}{c|cc}
\hline Cutting parameter & Value & \\
\hline Tool diameter, $\varnothing(\mathrm{mm})$ & 20 & \\
Number of tooth & 1 & \\
Feed per tooth $(\mathrm{mm})$ & 0.1 & \\
& & Insert \\
& & carbide
\end{tabular}
and cutting force

\begin{tabular}{|c|c|c|}
\hline \multicolumn{2}{|c|}{$\begin{array}{l}\text { Tool revolution (RPM) } \\
\text { Cutting speed (m/min) for (a), (b) and } \\
\text { (c) only }\end{array}$} & $\begin{array}{c}540,1460,2270,2920,4540 \\
33.772,91.308,141.966 \\
182.617,283.932\end{array}$ \\
\hline \multirow{2}{*}{$\begin{array}{l}\text { (a) } A_{d} \text { of } \\
\text { cut experi- } \\
\text { ment }\end{array}$} & $\mathrm{R}_{\mathrm{d}}(\mathrm{mm})$ & 1.0 \\
\hline & $\mathrm{A}_{\mathrm{d}}(\mathrm{mm})$ & 1.0 \\
\hline \multirow{2}{*}{$\begin{array}{l}\text { (b) } \mathrm{R}_{\mathrm{d}} \text { of } \\
\text { cut experi- } \\
\text { ment }\end{array}$} & $\mathrm{R}_{\mathrm{d}}(\mathrm{mm})$ & $0.2,0.4,0.6,0.8,1.0$ \\
\hline & $\mathrm{A}_{\mathrm{d}}(\mathrm{mm})$ & $2.0,4.0,6.0,8.0,10.0$ \\
\hline \multirow{2}{*}{$\begin{array}{l}\text { (c) Cutting } \\
\text { speed } \\
\text { experiment }\end{array}$} & $\mathrm{R}_{\mathrm{d}}(\mathrm{mm})$ & 8 \\
\hline & $\mathrm{A}_{\mathrm{d}}(\mathrm{mm})$ & 0.5 \\
\hline \multirow{4}{*}{$\begin{array}{l}\text { (d) Wear } \\
\text { mechanism } \\
\text { experiment }\end{array}$} & $\mathrm{R}_{\mathrm{d}}(\mathrm{mm})$ & 1.0 \\
\hline & $\mathrm{A}_{\mathrm{d}}(\mathrm{mm})$ & 1.0 \\
\hline & Cutting length (mm) & 6000 \\
\hline & Cutting speed $(\mathrm{m} / \mathrm{min})$ & 283.932 \\
\hline
\end{tabular}

\subsection{Cutting Edge Temperature and Cutting Force Measurement}

Referring to Fig. 1, an infrared radiation is emitted at the cutting edge of cutting tools. As infrared waves behave like a light, it can travel through the optical fibre. Then it passes through a condenser to condense the infrared radiation before entering photocell. Infrared detectors (InAs \& InSb) in the photocell captures the infrared waves and convert it to voltage output using an amplifier. Whereas cutting force from the cutting process is obtained from the dynamometer. The experimental setup is shown in Fig. 1. The experiment is conducted by comparing cutting speeds and cutting depths with respect to its cutting edge temperature and cutting force respectively.

Optical

fiber InAs Photocell Amplifier

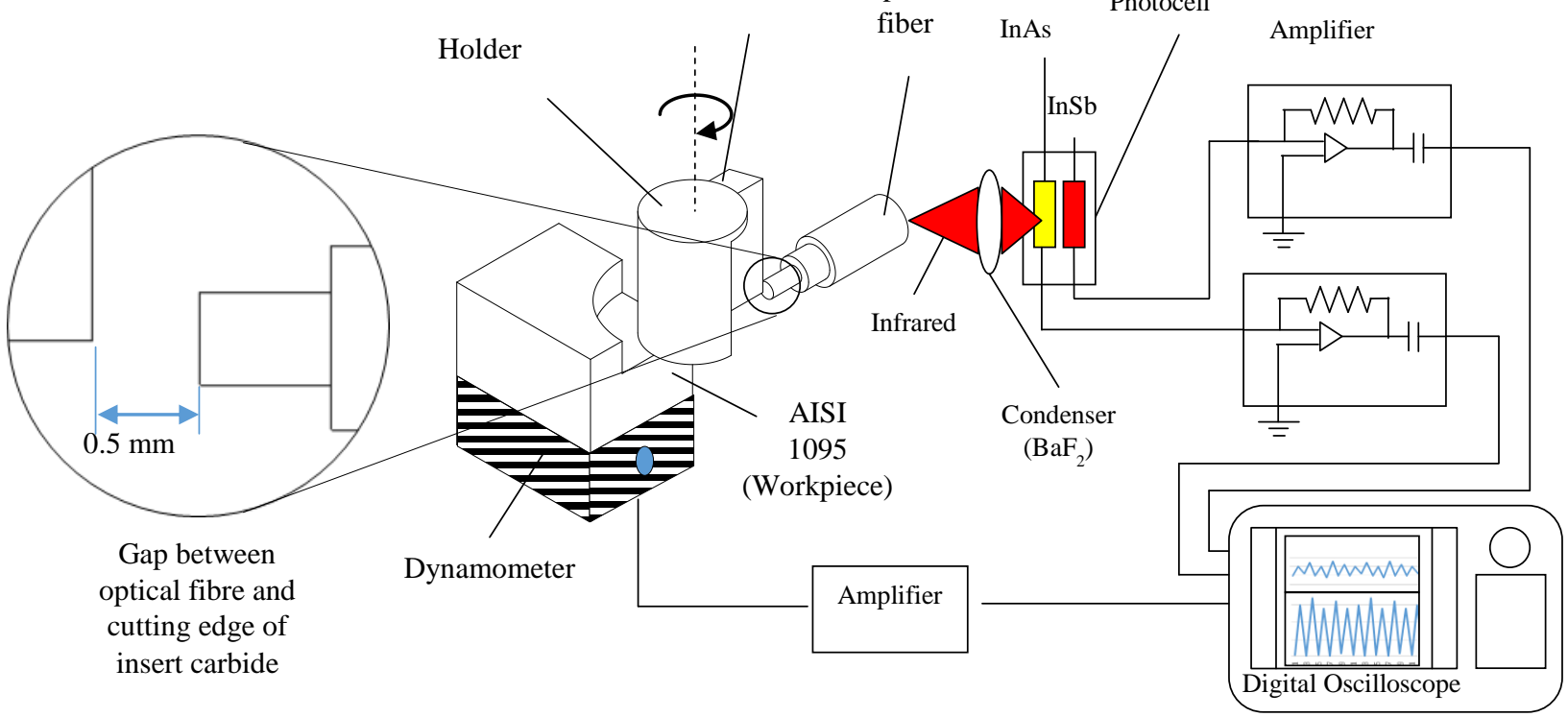

Fig. 1: Experimental setup of cutting edge temperature and cutting force measurement

\section{Results and Discussion}

\subsection{Cutting Profile}

Cutting edge temperature and cutting force profile are shown in Fig. 2. Each impulse resembles consecutive cuts in the milling process. At cutting speed of $283.93 \mathrm{~m} / \mathrm{min}$, cutting edge temperature is $333.6{ }^{\circ} \mathbf{C}$ while cutting force is $2 \mathrm{kN}$. The input of photocell sensor is delayed by $6.3 \mathrm{~ms}$ as the position of optical fibre is $180^{\circ}$ from the contact point of initial feed between cutting tool and workpiece (Fig. 6(a)). 

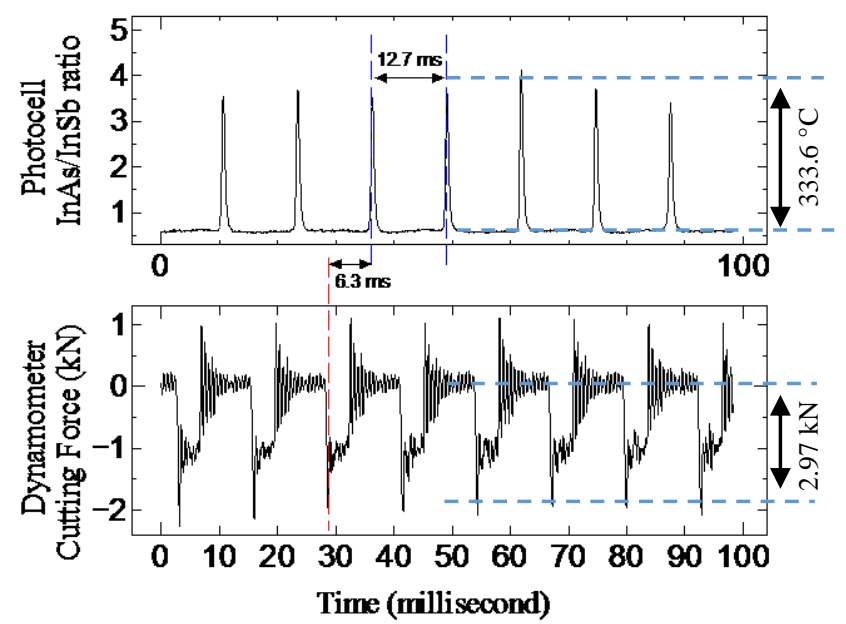

Fig. 2: Cutting edge temperature and cutting force profile at cutting speed of $283.93 \mathrm{~m} / \mathrm{min}$

\subsection{Impact of Axial and Radial Depth of Cut on Cutting Edge Temperature and Cutting Force}

Depth of cut in milling process has a significant impact on the cutting edge temperature and cutting force. As the material removal rate (MRR) increased, cutting edge temperature and cutting force in-creased (Fig. 3 and Fig.4). This is due to effective work done, which increased when the depth of cut increases.

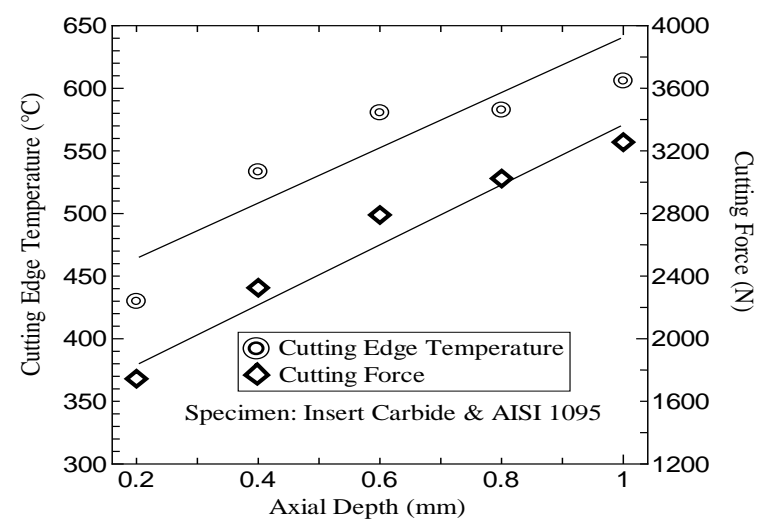

Fig. 3: Axial depth of cut $\left(A_{d}\right)$, cutting edge temperature, and cutting force

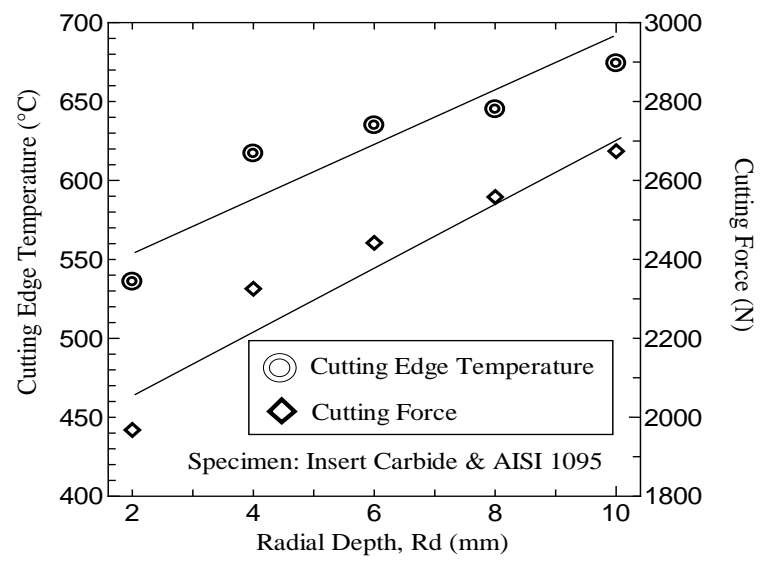

Fig. 4: Radial depth of cut $\left(R_{d}\right)$, cutting edge temperature, and cutting force

\subsection{Impact of Cutting Speed on Cutting Edge Tempera- ture and Cutting Force}

Relations of cutting speed of the cutting tool with cutting edge temperature and cutting force are shown in Fig. 5. The cutting edge temperature increases proportionally with cutting speed meanwhile, cutting force decrease with cutting speed. Thermal effects have the significant cause in decreasing trend of cutting force. The friction in the cutting tool-workpiece and cutting toolchip interfaces are resisting overtime and dissipates as thermal energy as discussed by [8]. The increasing cutting edge temperature has softened the mechanical strength of the workpiece's feed. As a result, work done required to cut a single pass in high cutting speed is less than in low cutting speed.

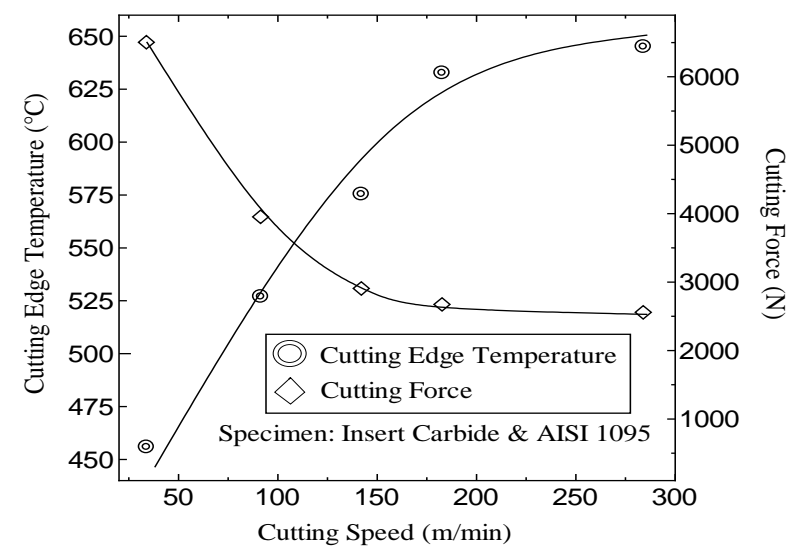

Fig. 5: Cutting speed affects cutting edge temperature and cutting force

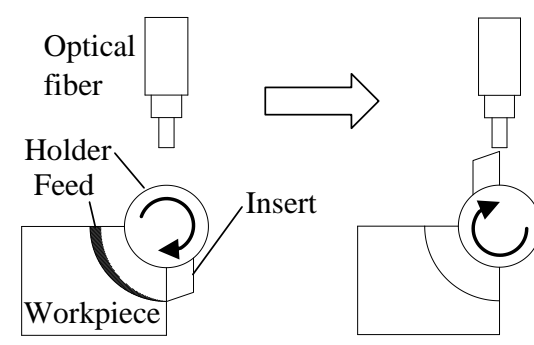

Fig. 6(a): Top view of cutting process

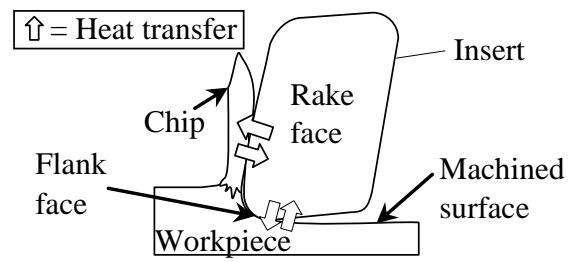

Fig. 6(b): Side view of cutting process

\subsection{Impacts of Wear on Cutting Edge Temperature and Cutting Force}

The prolonged use of cutting tool has increased the width of flank wear at the contact point of flank face and the workpiece's machined surface as shown in Fig. 6(b). Fig. 7(a), Fig. 7(b) and Fig. 7 (c) shows the development of flank wear after consecutive cutting length. The influence of flank wear on cutting edge temperature is shown in Fig. 8(a) which indicates significant effects.

Flank wear contributes to the development of cutting forces and increase the total area of abrasion. Increment of abrasive forces incites more thermal energy to be developed. Thus, these thermal energy escapes to surrounding in the form of infrared radiation. It is supported by a trend shown in Fig. 8(b) where cutting force increases together with a growth of flank wear's width. The ununiformed chipping (Fig. 7(b) and Fig. 7(c)) at the flank face of insert carbide was caused by abrasive friction between insert's flank face and workpiece's machined surface. As a conclusion, increment of flank wear has increased abrasive force in total cutting force and cutting edge temperature. 


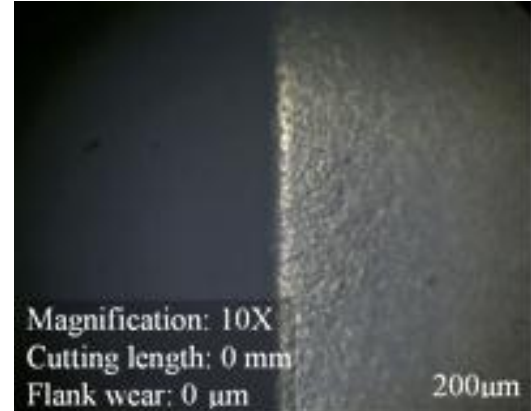

Fig. 7(a): Flank wear's width at initial cutting length

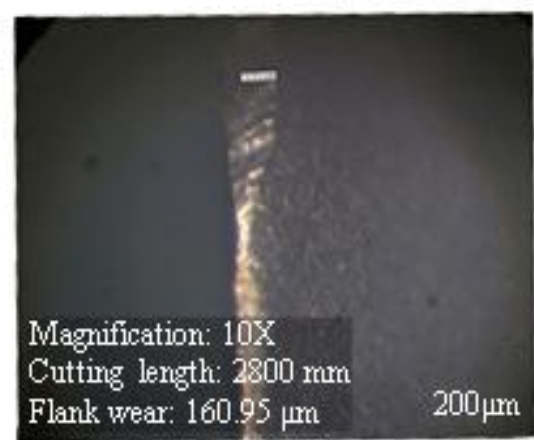

Fig. 7(b): Flank wear's width at cutting length of $2800 \mathrm{~mm}$

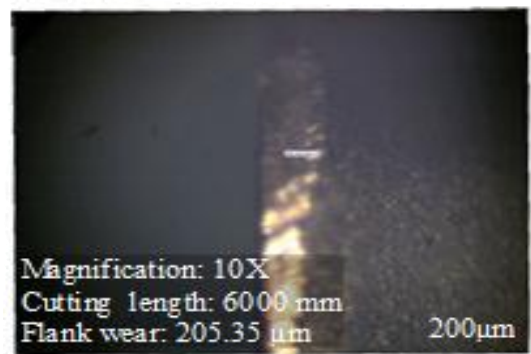

Fig. 7(c): Flank wear's width at cutting length of $6000 \mathrm{~mm}$

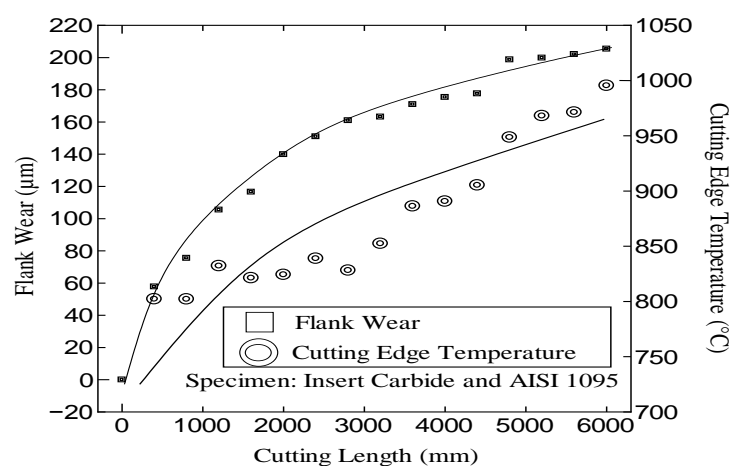

Fig. 8(a): Influence of flank wear on cutting edge temperature

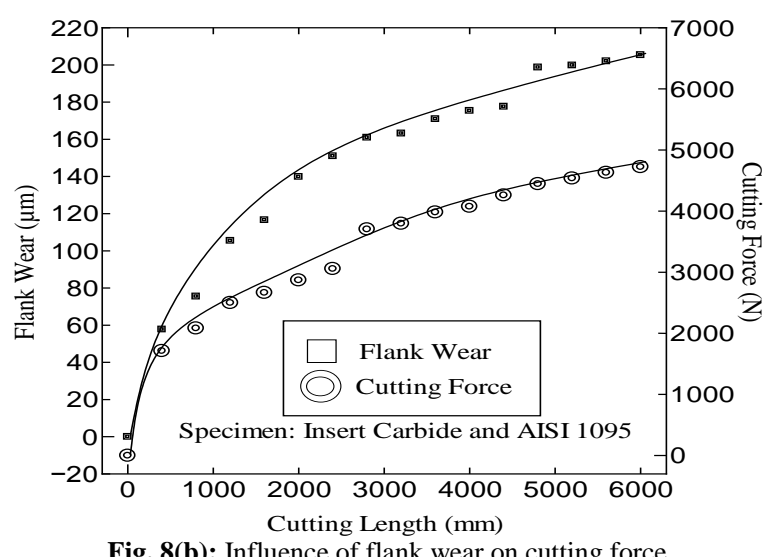

Fig. 8(b): Influence of flank wear on cutting force

\section{Conclusion}

In this paper, a study of cutting conditions on cutting edge temperature and cutting forces was carried out experimentally. The effect of cutting speed, depth of cut, and flank wear on cutting edge temperature were examined. The main results were analysed as follows:

a) Increasing depth of cut gives an increasing cutting edge temperature. It is due to work done required to remove additional MRR is increasing.

b) Higher cutting speed gives a decreasing cutting force and increasing cutting edge temperature. This condition is caused by the workpiece's mechanical strength is softened by heat interaction between cutting tool, chip and workpiece's machined surface while cutting edge temperature increase due to total friction increase at cutting tool-chip's interface and cutting tool-workpiece's interface.

c) Existence of progressing flank wear affects both cutting edge temperature and cutting force proportionally. The ununiformed chipping had cause increase in the friction total area and increasing thermal energy. It also affects the cutting pressure to be reduced significantly resulting in cutting force increase.

\section{Acknowledgement}

The authors are grateful to the Exploratory Research Grant Scheme: ERGS/TK01(01)/1007/2013 (04) for giving a fund assistance for this experiment.

\section{References}

[1] Ueda T, Sato M, Hosokawa A, Ozawa M (2008), Development of infrared radiation pyrometer with optical fibers - two-color pyrometer with non-contact fiber coupler. CIRP Annals - Manufacturing Technology 57(1), 69-72.

[2] Beno T, Hulling U (2012), Measurement of cutting edge temperature in drilling. Procedia CIRP 3(1), 531-536.

[3] Sato M, Tamura N, Tanaka H (2011), Temperature variation in the cutting tool in end milling. Journal of Manufacturing Science and Engineering 133(2), 021005.

[4] Yashiro T, Ogawa T, Sasahara H (2013), Temperature measurement of cutting tool and machined surface layer in milling of CFRP. International Journal of Machine Tools and Manufacture 70, 63-69.

[5] Di C, Zhang D, Wu B, Luo M (2017), An investigation of temperature and heat partition on tool-chip interface in milling of difficult-tomachine materials. Procedia CIRP 58, 49-54.

[6] Yassin A, Ueda T, Shazali STS (2012), Experimental study on machinability of laser- sintered material in ball end milling. International Journal of Mechanical, Aerospace, Industrial, Mechatronic and Manufacturing Engineering 6(11), 1816-1819.

[7] Onozuka H, Utsumi K, Kono I, Hirai J, Numata Y, Obikawa T (2015), High speed milling processes with long oblique cutting edges. Journal of Manufacturing Processes 19, 95-101.

[8] Ye GG, Xue SF, Ma W, Jiang MQ, Ling Z, Tong XH, Dai LH (2012), Cutting AISI 1045 steel at very high speeds. International Journal of Machine Tools and Manufacture 56, 1-9. 